\title{
POR UMA DEMOCRACIA PROFANADA: ENSAIO SOBRE A SACRALIDADE DA POLÍTICA A PARTIR DE GIORGIO AGAMBEN
}

\section{FOR A DEEP DEMOCRACY: A TEST ON THE SACRALITY OF POLICY FROM GIORGIO AGAMBEN}

\author{
Bruno Morais * \\ Vitor Veríssimo*
}

\section{RESUMO}

Este ensaio tem por objetivo fazer uma reflexão sobre a democracia representativa e seus problemas ontológicos de não possibilitar aos seus sujeitos um agenciamento ativo e protagonismo nas escolhas de todo o processo democrático. Assim, por meio da filosofia radical de Giorgio Agamben intentamos extrair no pensamento do autor a crítica ao conceito de representação política e como sua aplicação pelo Estado Democrático de Direito funciona, ao contrário do que se pretende nas Constituições firmadas pelos próprios Estados, numa barreira, ou nos termos agambenianos, numa sacralização do espaço político, que tem por objetivo a separação. Essa separação - o relegere - funciona então como dispositivo de poder para cercear o protagonismo político e limitá-lo a determinados agentes de poder. Do outro lado sua desativação passa por um processo de profanação, que se trata de restaurar as coisas separadas, tornando-as comuns - acessíveis ao uso comum. A partir disso propusemos uma reflexão sobre a operação dos dispositivos na democracia representativa e de como o modus operandi desse sistema é a exclusão e a exceção, e não, de fato, a participação.

PALAVRAS-CHAVE: Filosofia radical. Giorgio Agamben. Democracia radical. Democracia representativa. Participação política.

\begin{abstract}
This essay purpose is to make a reflection on representative democracy and its ontological problems of desabling its subjects an active agency and protagonism in the choices of the entire democratic process. Thus, through the radical philosophy of Giorgio Agamben we intend to extract in the author's thought the critique of the concept of political representation and how its application by the Democratic Constitutional State works, contrary to what is intended in the Constitutions signed by the states themselves, in a barrier, or in Agambenian terms, in a sacralization of political space, which aims at separation. This separation - the relegere - then acts as a power device to curb political protagonism and limit it to certain agents of power. On the other hand, its deactivation goes through a process of desecration, which is about restoring things apart, making them common - accessible to common use. From this we proposed a reflection on the operation of the devices in representative democracy and how the modus operandi of this system is exclusion and exception and not actually participation.
\end{abstract}

KEY-WORDS: Radical philosophy. Giorgio Agamben. Radical democracy. Representative democracy. Political participation.

\footnotetext{
* Doutorando em Direito e Justiça, mestre em Direito e Justiça e graduado em Direito pela Faculdade de Direito e Ciências do Estado da Universidade Federal de Minas Gerais. E-mail: Bmorais1950@ hotmail.com.

${ }^{* *}$ Mestrando em Ciências Sociais pela PUC Minas, graduado pela Faculdade Mineira de Direito (PUC Minas). E-mail: vitormaiav@hotmail.com.
} 


\section{INTRODUÇÃO}

Neste trabalho propomos um ensaio filosófico a partir da obra do filósofo italiano Giorgio Agamben. Um dos principais expoentes da filosofia radical no século $\mathrm{XX}$, e herdeiro do pensamento de Walter Benjamin, o autor propõe análises com intenso teor filosófico sobre a política e a sociedade contemporâneas.

Assim, nos valemos principalmente de sua obra para tecer comentários a respeito do problema da democracia representativa liberal nas sociedades ocidentais contemporâneas. Então, propusemos uma leitura a partir dos conceitos filosóficos de religião, sacralização e profanação, por meio da metodologia agambeniana da arqueologia filosófica.

Com essa chave hermenêutica tivemos por intenção ler a ideia de representação no escopo histórico da democracia ocidental e suas implicações dentro das instituições de poder que existem no Estado.

Por fim, com as contribuições de Andityas Matos e sua obra sobre democracia radical que se baseia no pensamento de Agamben, buscamos exemplificar como esses importantes conceitos filosóficos possuem reverberações no escopo social.

\section{RELIGIO E RELEGERE: A SEPARAÇÃO RELIGIOSA DO QUE É COMUM}

A partir da obra do filósofo italiano Giorgio Agamben é possível fazer importantes considerações a respeito dos aspectos "religiosos" da política. Optamos por colocar a palavra entre aspas porque, primeiramente, é preciso demonstrar os conceitos utilizados pelo mesmo autor a respeito dos termos religião, sagrado e profano. A partir do que pode ser chamado de arqueologia filosófica, Agamben busca explicar ideias que estão arraigadas no senso comum e propor uma outra interpretação sobre elas.

Assim ele explica, a partir de uma análise dos juristas romanos que "sagradas ou religiosas eram as coisas que de algum modo pertenciam aos deuses [...] [e] como tais elas eram subtraídas ao livre uso e ao comércio dos homens" (AGAMBEN, 2007, p. 58). Dessa forma, consagrar - ou sacrare - era "o termo que designava a saída das coisas da esfera do direito humano" (p. 58) e contrariamente, profanar era o ato que restituía tais coisas ao livre uso dos homens. A profanação então, poderia ser feita por meio do sacrílego, que era justamente "todo ato que violasse ou transgredisse" (p. 58) a indisponibilidade especial que as coisas sagradas possuíam. 
Comunicação: Por uma democracia profanada: ensaio sobre a sacralidade da política a partir de Giorgio Agamben

Esses atos consubstanciavam-se na ideia do que é "puro", sendo "o lugar que havia sido desvinculado da sua destinação aos deuses dos mortos, e já não era nem sagrado, nem santo, nem religioso, libertado de todos os nomes desse gênero" (AGAMBEN, 2007, p. 58). Com isso, Agamben (p. 58) define por religião "aquilo que subtrai coisas, lugares, animais ou pessoas ao uso comum e as transfere para uma esfera separada". Para ele, não existe religião sem separação e, da mesma forma, toda separação irá envolver, necessariamente, um núcleo religioso.

É a partir dessa concepção que Agamben afirma que religio não é, como se costumou conceber, oriundo de religare (que liga divino e humano), mas de relegere, indicando uma "atitude de escrúpulo e de atenção que deve caracterizar as relações com os deuses, a inquieta hesitação (o 'reler') perante as formas - e as fórmulas - que se devem observar a fim de respeitar a separação entre o sagrado e o profano" (AGAMBEN, 2007, p. 59). Dessa forma, religio não é o elo entre seres humanos e divinos, mas, ao contrário, é aquilo os mantém distintos, separados.

Vê-se então, a enunciação importante que faz o filósofo sobre a origem desses termos. Religião é, nesse aspecto, o que separa as dimensões do divino e do humano, do sagrado e do profano. É este último, porém, outro importante conceito para a compreensão do pensamento do filósofo, a profanação. Para ele, profanar "significa abrir a possibilidade de uma forma especial de negligência, que ignora a separação, ou melhor, faz dela um uso particular". Assim a profanação é justamente a restituição ao uso comum "do que havia sido separado na esfera do sagrado" (AGAMBEN, 2007, p. 59).

Um outro ato que proporciona a transgressão entre os limites do divino e do humano do sagrado e do profano - é a secularização. Agamben (p. 60) entende que "a secularização é uma forma de remoção que mantém intactas as forças, que se restringe a deslocar de um lugar a outro". Ou seja, depreende-se que, apesar de agir, formalmente, com aparência de transgressão entre os limiares da religião e do comum, a secularização não profana, mas apenas desloca as forças de lugares. O autor exemplifica este ato, dizendo que "a secularização política de conceitos teológicos [...] limita-se a transmutar a monarquia celeste em monarquia terrena, deixando, porém, intacto seu poder (p. 60-61). Em outras palavras, a secularização promove alterações aparentes nas forças e no poder (que promovem e distinguem o que é divino e o que é humano), mas não são capazes de irromper a separação ou melhor - não são capazes de promover um religare (entre deuses e humanos) mas apenas são outra forma do relegere (manter intactas as formas religiosas e profanas das coisas). 
É esta a insuficiência da secularização diante da profanação. Enquanto aquela, como dissemos, meramente altera as fórmulas, sem promover mudanças estruturais na natureza das coisas, esta - a profanação - é capaz de romper a separação do sagrado e, profanando-o, restitui as coisas ao uso comum. É o que Agamben chama de neutralização: "o que estava indisponível e separado perde a sua aura e acaba restituído ao uso". As consequências de ambos também se divergem, como explica Agamben a partir de uma análise de sua dimensão política: ambas as operações são políticas, mas a primeira tem a ver com o exercício do poder, o que é assegurado remetendo-o a um modelo sagrado; a segunda desativa os dispositivos do poder e devolve ao uso comum os espaços que ele havia confiscado (AGAMBEN, 2007, p. $61)$.

Ora, para Agamben, é indissociável a ideia de separação e religião. Tanto a religião implica separação, quanto toda separação possui algo de religioso. É crasso que a religião irá, inevitavelmente, envolver a distinção do que é possível e tangível aos humanos, e aquilo que não lhes pertence, pois é de uso exclusivo do divino. Assim, o que é sagrado não pode ser comum, e o contrário se faz verdadeiro.

Outrossim, mais um limiar que trabalha o filósofo - pois em sua obra é comum a utilização desse pensamento limiar, ou seja, zonas de indeterminação entre conceitos, em tese, essencialmente opostos - é o da profanação e da neutralização. Como já explicamos, ambos são ações que têm por motivo uma transgressão das zonas de separação e do comum, porém com uma diferença básica: a profanação produz alteração estrutural, uma vez que é capaz de transpassar a barreira do que mantém o separado e trazê-lo para o uso comum, o uso livre.

\section{OS DISPOSITIVOS E O USO SAGRADO}

É necessário, contudo, fazermos breve interrupção no raciocínio para trazer outros conceitos importantes do mesmo Agamben para nossa proposta.

Agamben utiliza da metodologia à qual chama de arqueologia filosófica para investigar não só a origem de certos fenômenos e conceitos que trabalha, mas também para propor usos (e desusos) desses mesmos conceitos numa teoria filosófica sobre a política. Por isso, irá entender esses conceitos como paradigmas. Para ele, paradigmas podem ser entendidos, em suma, como sinônimos de exemplos. Explica-se: utiliza-se da ideia de paradigmas para buscar uma fuga das polaridades entre universalidade e particularidade. Assim, o exemplo não é nem particular, nem universal. Ou seja, o exemplo, ao se excluir do 
Comunicação: Por uma democracia profanada: ensaio sobre a sacralidade da política a partir de Giorgio Agamben

caso geral, deve-se excluir da materialidade do objeto, assim, desativa (ou profana), se põe fora das estruturas gerais de pensabilidade de uma realidade.

Nas palavras do autor, “o paradigma é um caso singular que se isola do contexto do que é parte sozinho, [...] [pois] exibindo sua própria singularidade, volta inteligível a um novo conjunto cuja homogeneidade ele mesmo deve constituir" (AGAMBEN, 2010, p. 23). Da mesma forma, "paradigma implica um movimento que vai da singularidade à singularidade e que, sem sair desta transforma cada caso singular em exemplar de uma regra geral que nunca pode formular-se a priori” (p. 29).

A ideia de paradigma como exemplo se mostra na intenção de demonstrar que o pensamento não precisa se subsumir às categorias históricas de interpretação, e por isso o método arqueológico: investigar a arché - ou, a origem - dos termos. É nesse sentido que Agamben afirma que no paradigma não há uma origem, ou uma arché, mas que todo fenômeno é a origem, e toda imagem é "arcaica” (AGAMBEN, 2010, p. 41).

Se pensarmos que esse recorte filosófico se insere na obra do autor dentro de reflexões sobre a política e a sociedade, é possível compreender a importância desse exercício para ler a história como exemplo - longe das particularidades e generalidades - e, assim, profanar o que está posto - como divino, separado - ao uso livre dos humanos, do comum. Exemplificando, entender que toda experiência histórica da política é por si um paradigma, ou seja, um exemplo e uma origem em si mesmo, significa compreender exatamente que tais categorias uma forma de estado, uma teoria política sobre governo, uma experiência de democracia não possuem regras gerais de conhecimento (a priori). Ou seja, esses exemplos foram historicamente experimentados e não podem ser sacralizados dentro da experiência histórica de toda a humanidade.

Nesse mesmo escopo Agamben, a partir da obra de Michel Foucault, irá trabalhar o conceito de dispositivo. Na leitura que fez de Foucault, Agamben depreende dispositivo como resultado do cruzamento de relações de poder e de relações de saber, exercendo sempre uma função estratégica concreta, se inscrevendo, sempre, numa relação de poder (AGAMBEN, 2009, p. 29).

Porém, utilizando de sua metodologia típica - a arqueologia filosófica, como explicamos -, Agamben buscou conhecer a origem do termo dispositivo, ou dispositio. A partir do conceito teológico de oikonomia ${ }^{1}$. Dessa forma a

\footnotetext{
1 Remontando à teologia cristã medieval, quando buscava-se conhecer e conceber a noção da Trindade, Agamben conta que filósofos como Tertuliano, Hipólito e Irineu se utilizaram do termo oikonomia - ou a
} 
oikonomia torna-se assim o dispositivo mediante o qual o dogma trinitário e a ideia de um governo divino providencial do mundo foram introduzidos na fé cristã. [...] A fratura que os teólogos procuraram deste modo evitar e remover em Deus sob o plano do ser reaparece na forma de uma cesura que separa em Deus ser e ação, ontologia e práxis. A ação (a economia, mas também a política) não tem nenhum fundamento no ser: esta é a esquizofrenia que a doutrina teológica da oikonomia deixa como herança à cultura ocidental. (AGAMBEN, 2009, p. 37).

Ora, é justamente a partir dessa des-subjetivização do ser, ou seja, a separação entre ontologia e práxis que se insere a concepção de dispositivo de Giorgio Agamben. Para ele, em suma, dispositivo é tudo o que não é ser vivente, uma vez que o termo dispositivo evidencia "uma atividade de governo sem nenhum fundamento no ser", e é justamente por isso, que "os dispositivos devem sempre implicar um processo de subjetivação, isto é, devem produzir o seu sujeito" (AGAMBEN, 2009, p. 38).

É nesse aspecto que podemos ver um ponto de encontro entre o pensamento de Foucault e de Agamben. Ambos concebem a ideia e dispositivo como instrumentos de poder nas relações capazes de impor ou coibir comportamentos. Para Agamben (2009, p. 40), dispositivo é "qualquer coisa que tenha de algum modo a capacidade de capturar, orientar, determinar, interceptar, modelar, controlar e assegurar os gestos, as condutas, as opiniões e os discursos dos seres viventes".

Dessa forma enxerga-se como os dispositivos guardam relação com ideia da separação, constituindo-se como importante atributo do pensamento agambeniano. Sendo capaz de subtrair o ser das coisas, ou seja, promovendo a des-subjetivação, o dispositivo é o instrumento que irá promover a separação, a retirada do uso humano e a consagração para o uso divino. Dessa feita, o dispositivo é tanto uma máquina que produz subjetivações - pois des-sujeitar é também produzir um sujeito outro - enquanto também máquina de governo (uma vez que a produção de exclusão é técnica de governo para Agamben, como veremos a seguir) (AGAMBEN, 2009, p. 46).

\section{SACRALIZAÇÃO DA POLÍTICA E A EXCEÇÃo COTIDIANA}

É preciso então, tal qual a metodologia de Agamben, investigar arqueologicamente conceitos postos sobre a democracia representativa, sendo esta a forma dominante pela qual se exerce a política na maior parte dos Estados ocidentais.

"arrumação" dos negócios da casa - para explicar como Deus, em seu ser ou substância era uno, mas quanto a sua oikonomia, ou a maneira como administra o mundo (sua casa), é tríplice (AGAMBEN, 2009, p. 37). 
Comunicação: Por uma democracia profanada: ensaio sobre a sacralidade da política a partir de Giorgio Agamben

Assim, Hanna Pitkin (1967, p. 3) entende que o termo representação tem origem latina, também na Roma Antiga, a partir do termo repraesentare que tinha por significado "tornar presente ou manifesto" ou ainda "apresentar novamente". Inicialmente a palavra "representar" se aplicava para imagens ou objetos que encarnavam abstrações que "ocupavam o lugar de ou correspondem a algo ou alguém" (PITKIN, 2006, p. 19-20).

Ou seja, o verbete tinha por significação a ocupação de uma lacuna, o que nos remete ao conceito de Agamben de dispositivo e sua relação com a produção de um sujeito a partir da des-subjetivação. Concomitante a isto, "é preciso ressalvar que o seu significado original latino citado anteriormente, que concebe a representação como tornar presente algo ausente, já é bastante próximo do conceito de representação política" (LIMA, 2018, p. 11).

Nesse sentido, é preciso desvelar o "'mito de Atenas', cuja cultura em geral desde então serve de referência para o mundo ocidental, sobretudo em razão do surgimento do modelo político democrático" (LIMA, 2018, p. 16)². Apesar de não haver consenso dos estudiosos a respeito da ideia da representação na democracia grega (p. 27), essa "Atenas idealizada, então, é colocada como reino ético, ponto de reconciliação total e totalidade ética, onde a vida privada não se opõe à vida pública e vice-versa. [Nela] o homem se integra no todo e assim cidade e cidadão se tornam um só” (p. 16).

No medievo, contudo, a representação política "tem uma função declarativa de uma ordem hierárquica já dada e intrinsecamente legítima, justificada teologicamente, não sendo constitutiva como a representação moderna" (LIMA, 2018, p. 28).

Já na modernidade, as ideias de representação e democracia passam pelo conceito de soberania. Apesar das contribuições originárias de Jean Bodin, Thomas Hobbes, Jean-Jacques Rousseau e outros (que não é nosso propósito trabalhar aqui), a soberania se mostra como parte fundamental para a vida social e política, uma vez que, sem um representante que pessoalize - ou subjetive des-subjetivando - a força política do soberano (ou do "povo" a partir das concepções liberais), não há vida possível (LIMA, 2018, p. 31).

Nessa mesma toada de uma rápida passagem histórica, os movimentos socialistas que perderam seu caráter transformativo-revolucionário por meio da captura pela burocratização das democracias pela monopolização dos partidos (LIMA, 2018, p. 42), bem como no paradigma do Estado Democrático de Direito os movimentos sociais que propuseram enfrentamento aos regimes de forte teor do neoliberalismo econômico, "ao se aproximar do

\footnotetext{
${ }^{2}$ Não é o propósito deste trabalho fazer um remonte histórico-conceitual da democracia e suas implicações, nesse sentido remetemos o leitor caso interesse ao trabalho mencionado nesta citação.
} 
poder constituído, perderam seu vigor transformativo e comprometeram consideravelmente sua legitimidade em seu agir político" (LIMA, 2018, p. 51-52).

Esse sucinto remonte histórico é sintetizado por Agamben no que chama de estado de exceção, para o qual essa "exceção cotidiana” (LEAL; THIBAU, 2015) se utiliza do sistema jurídico-político como uma “máquina letal” (AGAMBEN, 2004, p. 130-131).

A atuação, porém, dessa máquina, embora claramente autoritária, atua numa zona de incertezas entre a política e o direito - anomia e o próprio nomos. Essa instrumentalização se consubstancia numa "guerra civil legal" que "permite a eliminação física não só dos adversários políticos, mas de categorias inteiras de cidadãos, que por qualquer razão, pareçam não integráveis ao sistema político”. Agamben (2004, p. 13) continua: o estado de exceção tem se apresentado como um "paradigma de governo", mais ainda, uma "técnica de governo", apresentando-se assim num "patamar de indeterminação entre democracia e absolutismo".

Apesar de aceitar a condição do estado de dominação de humanos sobre humanos, essa violência, ao nosso ver, se dá em virtude da instrumentalização do Estado, como produtor de exceção, com o fim de estabelecer um controle sobre os mecanismos políticos em um determinado território, utilizando então, a partir disso, da exclusão de certas camadas da população na ingerência da produção da política na sociedade.

O que se tem, então, é que, sob a alcunha da política, as forças dominantes que produzem o Estado (de exceção) para fazer valer seu projeto se utilizam dos dispositivos institucionais para transformar experiências "exemplificativas" como categorias históricas universais. Desta feita, o "paradigma" de governo se torna a exceção, sendo, assim, o principal dispositivo que opera a política - a democracia representativa - nas sociedades ocidentais.

É preciso então entender as maneiras pelas quais Giorgio Agamben busca compreender as formas de atuação da democracia enquanto dispositivo, pois esta propõe uma separação por meio da representação. Explicando, ela des-subjetiva o agente (quando este é representado) e sacraliza a política: apenas os representantes atuam na esfera sagrada, e os comuns (aqueles cujos objetos inanimados os representam) se encontram separados e relegados.

\section{PROFANAÇÃo E RESTITUIÇÃo}

Como pontuamos acima, a profanação é justamente esse ato que transgride a separação do sagrado e restitui os objetos ao uso comum dos humanos. Esse ato produz, como 
Comunicação: Por uma democracia profanada: ensaio sobre a sacralidade da política a partir de Giorgio Agamben

afirmamos, o que Agamben concebe como dimensão do que é "puro", uma vez que fora restituído após ter sido sacralizado. Concebe então o autor que "puro, profano, livre dos nomes sagrados, é o que é restituído ao uso comum dos homens. Mas o uso aqui não aparece como algo natural; aliás, só se tem acesso ao mesmo através de uma profanação" (AGAMBEN, 2007, p. 58).

A ocorrência da profanação, para o autor, se dá com o jogo. O jogo é um "reuso totalmente incongruente do sagrado". Remontando à história das brincadeiras infantis e suas origens sagradas - como por exemplo, brincar de bola como uma representação da disputa entre os deuses pela posse do Sol - Agamben mostra como o jogo é capaz de quebrar a unidade do sagrado, liberando a humanidade da esfera do sagrado e, sendo prático, entende que "a religio não mais observada, mas jogada, abre a porta para o uso, mas também as potências da economia, do direito e da política, desativadas em jogo, tornam-se a porta de uma nova felicidade" (AGAMBEN, 2007, p. 59-60).

É evidente a relação impossível entre o jogo e o repraesentare. Se o jogo envolve a participação, o uso negligente separa, sacraliza, ou no máximo neutraliza esses campos de atuação a partir dos dispositivos. Aliás, entende que os discursos formais (da democracia, da política, do Estado) afirma que o problema dos dispositivos é justamente um "mau uso". Não são desconhecidas por nós tais inferências. Agamben contraria essa ideia ao entender que "é totalmente impossível que o sujeito do dispositivo o use "de modo correto"" (AGAMBEN, 2009, p. 48). O que é dito dentro desse discurso do "modo correto" de usar os dispositivos pode, no máximo, incorrer na neutralização, que não passa de um deslocar inócuo das forças, mas que não é capaz de, como no jogo, negligenciar e propor um reuso - que é radicalmente diverso do uso sagrado, ainda que neutralizado - dos dispositivos.

É nesse sentido que "os mecanismos da democracia parlamentar indicam a possibilidade teórica (e espetacular) da tomada do poder pelas classes oprimidas ao mesmo que, na prática, a obstrui" (MATOS, 2015, p. 228). Os discursos inflamados pela democracia representativa (fruto das revoluções burguesas) agem dessa forma, sob promessas de alterações estruturais que não passam de deslocamentos das forças dentro dos mecanismos propostos pelos dispositivos - neutralizações -; e exemplos disso não faltam.

Por isso, "a representação só une porque separa; [...] o que significa que a forma de socialização do poder que os parlamentos fingem realizar existe apenas na dimensão retórica, sempre desembocando na separação" (MATOS, 2015, p. 229). Essa é uma importante reflexão sobre o pensamento agambeniano. É preciso entender que a desativação desses 
dispositivos - ou a criação do jogo - passa pela "criação de estruturas radicais de democracia nas quais seja impossível distinguir entre decisão e discussão" (p. 232). Isso porque, se no repraesentare a decisão ocorre na dimensão sagrada do relegere - quando se elege para o lugar de - uma estrutura que não separe o que é comum do que é sagrado (exercício comum da política e o voto), é capaz de promover a negligência da esfera divina, trazendo a liberação prometida pelo jogo.

Entendemos, a partir do pensamento agambeniano, que tais dispositivos, como exemplifica o autor no "estado de exceção", funcionam justamente a partir dessa tecnologia de produção da exclusão, da subjetivação e da des-subjetivação. Seria, pois, "correto" o uso que conseguisse escapar da lógica de subjetivação/des-subjetivação dos dispositivos; tirá-lo do escopo sagrado que exclui e trazê-lo à dimensão do comum, por meio do jogo, da brincadeira, promovendo verdadeira liberação da humanidade.

\section{CONCLUSÃO}

Resta então a compreensão do que Agamben trouxe como o puro. É aquilo que é restituído à dimensão comum. É preciso compreender que, para o autor, as coisas estão-aí-nomundo, como a concepção heideggeriana ensina, e por isso não há nada naturalmente sagrado. O sacrare é responsável por essa primeira separação das coisas, e só a profanação pode transgredir essa sacralização e restituir as coisas ao uso comum dos humanos.

O desafio da democracia radical, ou de qualquer outra forma que se proponha a jogar com a democracia representativa enquanto dispositivo de poder é justamente este, de restituir a política ao uso comum. Para tanto, será necessário justamente o des-uso desse dispositivo, a negligência profana que consegue a des-subjetivação que o repraesentare proporciona.

Dentro de seu exercício filosófico, Agamben não adentra no mérito de como é possível à humanidade estruturar a política de forma "profana". Sua obra apenas deixa pistas de onde é possível partir, e cabe a demais pensadores e pensadoras, da teoria política e demais áreas, conceber essa forma.

Contudo, como buscamos apresentar neste ensaio, é preciso distinguir entre a neutralização e a profanação. A democracia tem passado, ao longo dos séculos, por transformações de caráter meramente estéticos, que alteram seu formato e apresentação, mas mantém a separação entre o comum e o sagrado, proporcionando apenas deslocamentos de força dentro dos próprios dispositivos. Qualquer alteração que se proponha, de fato, 
Comunicação: Por uma democracia profanada: ensaio sobre a sacralidade da política a partir de Giorgio Agamben

profanatória, terá que se radicalizar na ideia do jogo, e negligenciar, tal qual fazem as crianças, as regras que separam o divino e o humano.

\section{REFERÊNCIAS}

AGAMBEN, Giorgio. Estado de exceção. 2. ed. São Paulo: Boitempo Editorial, 2004.

AGAMBEN, Giorgio. Profanações. São Paulo: Boitempo Editorial, 2007.

AGAMBEN, Giorgio. O que é um dispositivo? Tradução Nilcéia Vadati. In: AGAMBEN, Giorgio. O que é o contemporâneo? E outros ensaios. Chapecó: Argos, 2009. p. 25-51.

AGAMBEN, Giorgio. ¿Que és un paradigma? In: AGAMBEN, Giorgio. Signatura rerum: sobre el método. Tradução Flavia Costa y Mercedes Ruvituso. Barcelona: Anagrama, 2010. p. $11-42$.

LEAL, André Cordeiro; THIBAU, Vinícius Lott. A dogmática processual e a exceção cotidiana. Revista Brasileira de Direito Processual - RBDPro, Belo Horizonte, ano 23, n. 92, p. 13-29, out./dez. 2015.

LIMA, Bruno Morais Avelar. As manifestações de junho de 2013 e a representação política. Dissertação (mestrado) - Universidade Federal de Minas Gerais, Faculdade de Direito. 2018. (Orientador: Andityas Soares Moura Costa Matos).

MATOS, Andityas Soares de Moura Costa. Filosofia radical e utopias da inapropriabilidade: uma aposta an-árquica na multidão. Belo Horizonte: Fino Traço, 2015.

PITKIN, Hanna Fenichel. The concept of representation. Berkeley: University of California Press, 1967.

PITKIN, Hanna Fenichel. Representação: palavras, instituições e ideias. Tradução Wagner Pralon Mancuso e Pablo Ortellado. São Paulo: Lua Nova, n.67, p. 15-47, 2006. 